\title{
commentary
}

\section{Climate change narratives}

\author{
Richard D. Pancost
}

\section{Reconstructions of Earth's past are much more than benchmarks for climate models. They also help us comprehend risk by providing concrete narratives for diverse climates.}

\begin{abstract}
n central Spain, outcropping on dusty hillsides overlooking apparently endless miles of gnarled olive trees, is the Esplugafreda Formation. The Formation consists of hundreds of metres of rustycoloured palaeosols and the remains of ancient channels, part of a more-than-55million-year-old braided river system. What is particularly striking about these rocks is that atop them sits the Claret Conglomerate, a unit not of silt, sand and ancient soil, but of pebbles, fist-sized stones and even boulders. These stones are part of the same river system but were deposited under conditions with far more energy: the Conglomerate represents a relatively transient moment in Earth history of remarkably intense rainfall events. And these events were probably caused by ancient global warming.

Palaeoclimatologists have long argued that working out past climates can help us better anticipate the future, anthropogenically influenced world. This is especially true as we reach atmospheric carbon dioxide concentrations of over $400 \mathrm{ppm}$, a level that our planet has probably not experienced for 3 million years ${ }^{1}$. Indeed we are continuing
\end{abstract} towards $800 \mathrm{ppm}$, on a path that seemed less likely to continue unabated following the Paris Agreement, but remains feasible especially now that President Donald Trump has announced the United States' withdrawal from the Agreement. Such high concentrations of atmospheric carbon dioxide have probably not been experienced for about 30 million years ${ }^{2}$.

Ancient climates allow us to test the climate models on which future projections are based. They allow us to explore the impacts of climate change on ecosystems and complex interlinked Earth system processes. And they allow us to identify important processes that have perhaps not yet been incorporated into climate models.

Earth history, however, has an even deeper role to play in the modern conversation and public understanding of climate change. It helps us comprehend and narrate what might happen in a warmer climate. And it can illustrate the uncertainty associated with climate change forecasting.

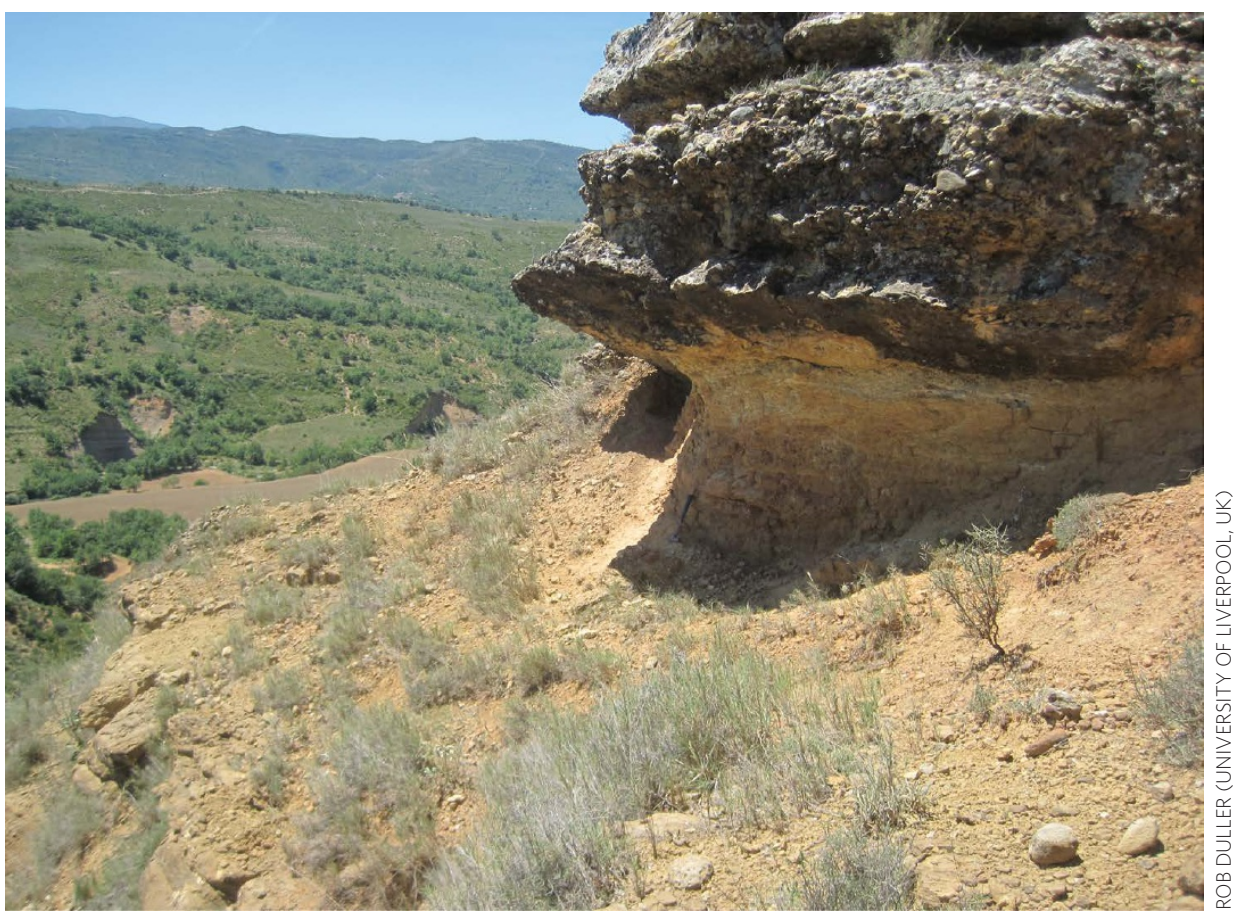

Figure 1 | The Claret Conglomerate outcropping in central Spain.

\section{The devil in the uncertainty}

There is much that we know; much that is known within certain probability distributions; much that is anticipated, but difficult to forecast due to system complexity; and much that remains unknown. This creates a hierarchy of uncertainty and risk in which poorly constrained climate change impacts can be conflated with - and cause confusion about - the more certain ones. We need to communicate the opposite: what is well understood in climate science contextualizes the more uncertain aspects.

Some aspects of anthropogenic climate change are now certain or near certain ${ }^{3}$ : atmospheric carbon dioxide and methane levels are increasing, both due to human activity; these increases have caused warming over the past half century and will cause further warming in the future. Warming will cause sea-level rise via thermal expansion and ice sheet melting, and future storms are likely to be associated with greater precipitation and more flooding as the moisture-holding capacity of the atmosphere increases. These are the tier-one insights of climate change science. But there is uncertainty with those estimates. How much warmer? How much more rain? How fast will ice sheets melt?

Uncertainty increases as our attention becomes more regionally focussed and our questions more detailed - especially with respect to ecological and societal impacts ${ }^{4}$. We do not know exactly where rainfall will increase or decrease; how that affects your particular city or the farmland from where your food comes; how a combination of more carbon dioxide, warmer air, and changes in rainfall and soil moisture affect forests and savannahs; or how those factors - combined with ocean acidification - affect coral reefs, marine ecosystems and global fisheries. 
We are making great strides in reducing these uncertainties, whether it be via more sophisticated Earth system models, greater computational capacity or better understanding of underlying processes. But the uncertainty remains profound, especially, and unfortunately, for those aspects of climate disruption - from extreme weather to food production - that most concern policymakers, industry and the public. This disconnect between our robust understanding of climate change fundamentals and its specific and localized impacts is clear to anyone who works with decision-makers; it was certainly clear to me when Bristol developed its 50-year resilience strategy ${ }^{5}$ (with the support of the 100 Resilient Cities initiative of the Rockefeller Foundation). Scientists are relatively comfortable with the continuum of understanding, from certainty to deep uncertainty. But to those who do not consider it on a daily basis, it can cause profound confusion.

If we cannot even predict how rainfall in the southwest of England will change, do we understand anything? Of course we do. What we do understand sharpens our concern about the risks that we do not. But conveying that and providing meaningful guidance in that context is challenging.

\section{Past and future}

Palaeoclimate provides a vital and powerful component to the cultural adoption of climate change understanding. Rather than asking decision-makers to understand a continuum of increasing uncertainty incorporated into Earth system models, from radiative forcing to cloud nucleation to biogeochemical feedbacks, and the associated emergent complexity, palaeoclimate research can present the same information as an experiential suite of observations and associated narratives.

Primarily, Earth history shows us that climate can change. We live during a particularly protracted period of climate stability - the Holocene - that has allowed civilization to thrive. Even on those relatively modest timescales of thousands of years, the concept of climate change has become embedded in our mythology and culture, from biblical floods to Dutch paintings of frozen canals.

The field of geology has ensured that we are well aware of the far more dramatic changes of Earth's deep history. Glacial striations in the American Midwest, coal deposits buried beneath deserts, vast salt deposits in the Mediterranean Sea and crocodile fossils in the Eocene Arctic have been incorporated into our cultural imagination, manifested as cinematic images of brachiosaurs trundling through hot swamps or herds of woolly mammoths foraging in the shadows of ice sheets.

But Earth's climate does not change randomly. It has changed and will continue to do so due to processes that are increasingly well understood. Crucially, our proxies for past carbon dioxide and temperature, despite their uncertainties and eccentricities, nearly universally show that when concentrations of carbon dioxide in the atmosphere were high, our planet was hot. Importantly, warming occurred in a manner consistent with climate models ${ }^{1,2}$ (although models appear to underestimate polar warming ${ }^{6}$ ), suggesting that to the first order, we understand the processes that govern Earth's temperature.

\section{Stories from deep time}

The Claret Conglomerate (Fig. 1) was deposited during a warming event known as the Palaeocene-Eocene Thermal Maximum (PETM), which occurred about 56 million years ago ${ }^{7}$. The evidence for an increase in carbon dioxide concentrations - a pronounced shift in the carbon isotopic composition of the atmosphere - is among the strongest in all of Earth's history ${ }^{8}$. Also robust is the evidence for pronounced global warming of 5 to $8{ }^{\circ} \mathrm{C}$, a response that is documented in numerous locations and by diverse proxies ${ }^{9}$.

We know that the carbon dioxide increase at the PETM caused the oceans to become more acidic - a direct chemical consequence of adding more carbonic acid to the oceans ${ }^{10}$. The Palaeocene and Eocene were also characterized by a lack of extensive continental ice and much higher sea level- evidence that Greenland and Antarctic ice sheets would eventually melt at elevated $\mathrm{CO}_{2}$ levels, and that in an essentially ice-free world the sea level can be 70 metres or more above today's levels, far more than the $\sim 1 \mathrm{~m}$ increase projected for the end of this century.

There are a multitude of similar stories from Earth history. Crucially, the relative simplicity of those observations provides the context for exploring more complex aspects of climate change in response to global warming.

The PETM Claret Conglomerate is evidence for more extreme rainfall. But it is more difficult to ascertain if it is evidence for a wetter climate in Spain or perhaps a drier climate with more intense and episodic events ${ }^{7}$. The same question can be asked of the change in clay assemblages deposited in marine sediments during the PETM or the widespread increase in sedimentation rates in marginal marine settings ${ }^{11}$. Other proxies, such as the hydrogen isotopic ratio of leaf waxes, suggest an increase in moisture transport to the poles ${ }^{12}$. Collectively, these data indicate that global warming caused a significant reorganization of the global hydrological cycle with significant meteorological change in many locations. That is a simple and powerful narrative, regardless of the uncertainty associated with the details (although those details remain important).

The PETM also allows us to explore the potential consequences for ecosystems. On land, floristic changes were widespread ${ }^{13}$, accompanied by soil faunal ${ }^{14}$ and mammalian dwarfism ${ }^{15}$. Soils, especially in continental interiors, became more barren. This could have been due to increased erosion or increased oxidation of organic matter under hotter and wetter conditions ${ }^{16}$. These changes on land appear to have profoundly affected the oceans. Intense storm events stripped soil from the land and delivered nutrients to the coastal seas, burying some ecosystems while providing nutrients for others. Degradation of the organic matter produced by algal blooms stripped oxygen from some marginal seas, including parts of what were to become the Gulf of Mexico, the Arctic Ocean and the Mediterranean Sea ${ }^{17}$. Life, both on land and in the sea, was profoundly transformed for tens of thousands of years.

The past does not necessarily predict risks associated with climate change but it assures us that they are real.

\section{To navigate uncertainty}

It is Earth system models on which we rely, and will continue to rely, for managing our uncertain future. Whether or not deep-time palaeoclimate observations will directly improve model-based forecasts for twenty-first-century global warming impacts, they have certainly contributed indirectly by unveiling gaps in our understanding, helping to constrain natural climate variability and confirming mechanisms underpinning climatic and biogeochemical responses.

Crucially, Earth history also informs how we engage with those forecasts. The past confirms that the risks expressed in Earth system models - from heatwaves, sea-level rise, flooding, drought and soil loss to enhanced stress on already stretched agricultural and natural systems - do exist. Natural global warming caused such things to happen in the past; anthropogenic global warming could cause them to happen again. By extension, risks that remain poorly understood should be a source of greater rather than lesser concern - we know enough to worry but, in some cases, 
not enough to plan. Consequently, such risks should motivate more rapid and bolder climate change mitigation, and not be an excuse to prevaricate ${ }^{18}$; at the same time, resilience to these risks must be creative and flexible.

Past climate research helps us anticipate the future. But it also subverts conventional ideas of mitigation and resilience by showing the complexity, variety and in some cases unpredictability of global warming consequences. In doing so, it has the potential to provoke new ways of anticipating our future, liberating creative and inclusive thinking and inspiring new types of solutions.

Richard D. Pancost is at the University of Bristol Cabot Institute, Royal Fort House, Bristol BS8 1UJ, UK.

e-mail:R.D.Pancost@bristol.ac.uk

\section{References}

1. Martinez-Boti, M. A. et al. Nature 518, 49-54 (2015).

2. Anagnostou, E. et al. Nature 533, 380-384 (2016)

3. IPCC Climate Change 2013: The Physical Science Basis (eds Stocker, T. F. et al.) (Cambridge Univ. Press, 2013).

4. IPCC Climate Change 2014: Impacts, Adaptation, and Vulnerability (Field, C. B. et al.) (Cambridge Univ. Press, 2014)

5. Bristol Resilience Strategy (Bristol City Council, 2016); http://go.nature.com/2rVP9fV
6. Valdes, P. Nat. Geosci. 4, 414-416 (2011).

7. Schmitz, B. \& Pujalte, V. Geology 35, 215-218 (2007)

8. Zachos, J. et al. Science 292, 686-693 (2001)

9. Dunkley Jones, T. et al. 125, 123-145 (2013).

10. Zachos, J. C. et al. Science 308, 1611-1615 (2005).

11. Handley, L. et al. 329, 10-21 (2012).

12. Pagani, M. et al. Nature 442, 671-675 (2006)

13. Wing, S. L. \& Currano, E. D. Am. J. Botany 100, 1234-1254 (2013).

14. Smith, J. J., Hasiotis, S. T., Kraus, M. J. \& Woody, D. T. Proc. Natl Acad. Sci. USA 106, 17655-17660 (2009).

15. Clyde, W. C. \& Gingerich, P. D. Geology 26, 1011-1024 (1998)

16. Cotton, J. M., Sheldon, N. D. Hren, M. T. \& Gallagher, T. M. Am. J. Sci. 315, 337-361 (2015).

17. Dickson, A. J. et al. Paleoceanography 29, 471-488 (2014).

18. Lewandowsky, S., Ballard, T. \& Pancost, R. D. Phil. Trans. R. Soc. A 373, 20140462 (2015).

Published online: 26 June 2017 